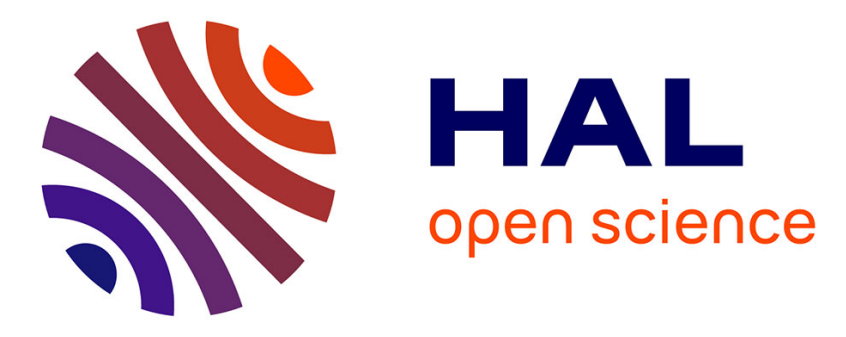

\title{
Mūsā b. al-Ḥasan al-Mawșilī et la correspondance des sultans rasūlides du Yémen. Genèse d'un ordre épistolaire
}

Eric Vallet

\section{- To cite this version:}

Eric Vallet. Mūsā b. al-Ḥasan al-Mawșilī et la correspondance des sultans rasūlides du Yémen. Genèse d'un ordre épistolaire. La correspondance entre souverains, princes et cités-Etats. Approches croisées entre l'Orient musulman, l'Occident latin et Byzance (XIIIe-début XVIe siècle), Dec 2008, Paris, EPHE, France. pp.127-146, 10.1484/M.MOM-EB.5.100969 . hal-00912304

HAL Id: hal-00912304

https://hal-paris1.archives-ouvertes.fr/hal-00912304

Submitted on 1 Dec 2013

HAL is a multi-disciplinary open access archive for the deposit and dissemination of scientific research documents, whether they are published or not. The documents may come from teaching and research institutions in France or abroad, or from public or private research centers.
L'archive ouverte pluridisciplinaire HAL, est destinée au dépôt et à la diffusion de documents scientifiques de niveau recherche, publiés ou non, émanant des établissements d'enseignement et de recherche français ou étrangers, des laboratoires publics ou privés. 


\title{
Mūsā b. al-Hasan al-Mawsilī et la correspondance des sultans rasūlides du Yémen Genèse d'un ordre épistolaire
}

\author{
Éric VALLET*
}

Édité en 1990 à Beyrouth, Al-burd al-muwaššă fĩ șinā'at al-inšă’ de Mūsā b. al-Ḥasan al-Mawsiilī (m. 699/1300) se présente au premier abord comme un objet de recherche facile à appréhender. Son éditrice, 'Afāf Sayyid Șabra, enseignante à l'université égyptienne d'al-Azhar, rapporte dans une brève préface les circonstances de sa découverte fortuite de l'ouvrage, sous la forme d'un manuscrit microfilmé conservé à Dār al-Kutub (n 848), alors qu'elle cherchait désespérément à travailler sur la pratique de l'inšă' à partir d'un recueil issu de la chancellerie mamlūke ${ }^{1}$. Son enquête préliminaire l'avait conduite vers trois textes, nous dit-elle: le premier, Al-miftāh al-munaššă fi hadīqat al-inšă de Ḍiyā' al-Dīn Ibn al-Ațīr (m. 637/1239), n'était qu'un "petit manuscrit qui ne répondait pas au but recherché», n'offrant "aucune matière scientifique au chercheur $»^{2}$. Un autre manuscrit anonyme,

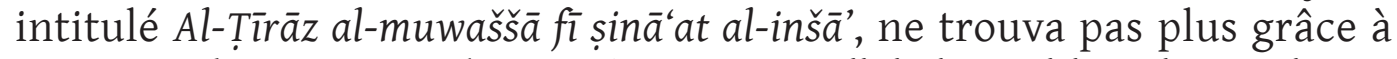
ses yeux, de même que le troisième, Mutawallī hidmat al-kuttāb min al-inšă wa-ba'd qawātid fann al-hisāb, qui présentait l'inconvénient d'avoir été rédigé en pleine période ottomane. Tout autre était l'importance historique du Burd de Mūsā b. al-Ḥasan al-Mawșilī, «témoignage authentique», selon 'Afāf Sayyid Șabra «des pratiques de la correspondance à l'époque ayyūbide et mamlūke» ${ }^{3}$.

En dix chapitres, cet auteur $\mathrm{du} \mathrm{vII}^{\mathrm{e}} / \mathrm{XIII}^{\mathrm{e}}$ siècle livre en effet à son lecteur un véritable guide épistolaire, envisageant les différentes parties de la correspondance: désignation de l'expéditeur (tarğama, chapitre 1, p. 49-50); formules d'identification du destinataire, distinguées selon son rang (muhățabāt, chapitre 2, p. 54-74); phrases initiales (istiftāhāat, chapitre 3, p. 75-78); surnoms honorifiques (alqāb, chapitre 4, p. 79-98); souhaits et salutations inaugurales ( $d u^{\prime} \bar{a}^{\prime}$ et salām, chapitres 5 et 6, p. 99-105); protocole final (chapitre 7, p. 106-108); souhaits finaux (chapitre 8, p. 109-124); propos et réponses adaptés à toutes les circonstances: fêtes, deuil, plainte, demande d'intercession, félicitations, etc. (chapitre 9, p. 125-187); vers poétiques classés par registres d'emploi (chapitre 10, p. 188-203). Aucune lettre n'est donnée intégralement, l'ouvrage se présentant plutôt comme un répertoire

* Université Paris 1 Panthéon-Sorbonne - evallet@univ-paris1.fr.

1. Mūsā b. al-Ḥasan al-Mawșilī, Al-burd al-muwaššă fișinā̌at al-inšă’, Beyrouth, 1990, p. 3 (abrégé: Burd).

2. Édité de longue date, ce texte présentait néanmoins suffisamment d'intérêt pour que Cl. Cahen lui consacrât un article: «La correspondance de Diyâa' al-Dīn ibn al-Athīr, liste de lettres et de textes de diplômes ", Bulletin of the School of Oriental and African Studies, vol. XIV, 1952, p. 34-43.

3. Burd, p. 3. 


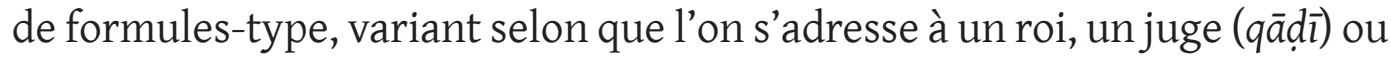
un maître artisan (ustād), toutes les catégories sociales étant soigneusement envisagées tour à tour. Le livre est solidement charpenté, présenté de manière à la fois élégante, systématique et concise - l'auteur ne dit pas avoir élaboré autre chose qu'un « résumé » (muhtașar) ${ }^{4}$. L'intention d'al-Mawșilī, rappelée dès la préface, est claire : montrer, une fois encore, que la chancellerie (kitābat al-inšă') est bien la plus illustre des charges exercée dans l'État, car « le calame [du secrétaire] est l'interprète de la langue des rois », le seul à même de prolonger l'éclat de leurs victoires et le lustre de leurs règnes ${ }^{5}$. Le Burd, rédigé dans la seconde moitié du VII ${ }^{\mathrm{e}} / \mathrm{XIII}^{\mathrm{e}}$ siècle, apparaît ainsi à son éditrice, comme le fondement solide sur lequel s'appuyèrent par la suite les secrétaires de la chancellerie mamlūke en Égypte et en Syrie, dont elle n'hésite pas à dresser une liste prosopographique détaillée en annexe de son ouvrage . $^{\circ}$.

On serait cependant bien en peine de trouver l'auteur du Burd, Mūsā b. al-Hasan al-Mawșilī, dans cette longue litanie de rédacteurs passés au service des maîtres du Caire et de Damas. Aussi paradoxal que cela puisse paraître, ce personnage, présenté comme le parangon du kātib mamlūk, donna toute la mesure de ses talents bien loin des rivages du Nil, comme l'atteste la notice biographique qui circulait à son sujet dans l'Égypte des $\mathrm{VIII}^{\mathrm{e}}-\mathrm{IX}^{\mathrm{e}} / \mathrm{XIV}^{\mathrm{e}}-\mathrm{XV}^{\mathrm{e}}$ siècles:

Son père faisait partie des secrétaires égyptiens de la chancellerie à l'époque d'al-Ẓāhir Baybars. Il était connu comme simsār al-hayr. Or, il arriva que son fils vint au Yémen en [6]60 lors d'une querelle (šahāna). Al-Muẓaffar, son souverain, l'accueillit et lui confia le dīwān al-inšă'. Il excella en cela et composa un ouvrage qu'il appela Al-Burd al-muwašša fi șinā'at al-inšă'. Tāğ al-Dīn 'Abd al-Bāqī a dit que l'ensemble des lettres envoyées par al-Muzaffar à al-Ẓāhir [Baybars], et même après, étaient de la rédaction de ce Tāğ al-Dīn [Mūsā b. al-Ḥasan al-Mawșilīi] .

Al-Mawșilī, modèle de l'inšă' mamlūk ? Cette notice ne laisse aucun doute sur le contexte de rédaction du Burd: le Yémen des Rasūlides et non Le Caire des sultans turcs. Ce contexte n'avait rien de fortuit, puisque Mūsā b. al-Hasan al-Mawșilī passa quarante années de sa vie auprès du souverain du Yémen, en occupant une fonction de premier ordre. Plus encore, son ouvrage est le seul manuel de chancellerie à avoir été composé au Yémen durant la période médiévale. C'est cette place singulière qu'il

4. Ibid., p. 46.

5. Ibid., p. 45.

6. Ibid., p. 229-307 (120 noms pour l'Égypte et 108 pour la Syrie).

7. Ibn Hặar al-'Asqalānī, Al-durar al-kāmina fí a'yān al-mi'a al-tāmina, éd. S. al-Karnūkī, Hayderabad, 1929-1931, vol. IV, p. 374, nº 1017 (notre traduction). Ibn Ḥağar dit tenir ces informations d'Ibn Faḍl Allāh al-'Umarī, mais nous n'avons trouvé nulle mention d'al-Mawșilī dans le chapitre des Masālik al-abșār fì mamālik al-amșār concernant le Yémen (éd. A. F. Sayyid, Le Caire, 1985, p. 149-163) ni dans le Ta'rïf bi-l-muștalaḥ al-šarîf, Le Caire, 1312 H., p. 21-22 sur les Rasūlides du Yémen. 
convient maintenant d'explorer, en reconsidérant l'œuvre d'al-Mawșilī dans le milieu où elle vit le jour, à l'abri des murailles de la citadelle de Ta'izz ou à l'ombre des palmeraies princières de Zabīd. Tout autant que les origines de son savoir, il s'agira de mesurer les enjeux et la portée fondatrice de son livre dans le cadre méconnu du puissant État qui domina l'Arabie du Sud à la fin du Moyen Âge.

Depuis le deuxième tiers du viI ${ }^{\mathrm{e}} / \mathrm{XIII}^{\mathrm{e}}$ siècle jusqu'au milieu du $\mathrm{IX}^{\mathrm{e}} / \mathrm{XV}^{\mathrm{e}}$ siècle, le sultanat rasūlide a profondément marqué l'histoire de la péninsule Arabique. Cette dynastie d'origine turcomane, héritière du royaume constitué dans le sud de la Péninsule par les Ayyūbides à la fin $\mathrm{du} \mathrm{VI}^{\mathrm{e}} / \mathrm{XII}^{\mathrm{e}}$ siècle, parvint à bâtir un État structuré et imposant, dominant un territoire allant de la région du Dhofar à l'est, aux limites du Hedjaz au nord (région de Halī b. Ya'qūb). Par son administration étoffée, son contrôle étroit de la production et des échanges, son influence au-delà des mers en direction de l'Inde ou de la côte africaine, le sultanat rasūlide s'affirma comme le premier État indépendant de type monarchique et bureaucratique dans une Arabie qui restait dominée par ailleurs par des pouvoirs essentiellement de nature tribale ${ }^{8}$. Si le fondateur de la dynastie, 'Umar b. 'Alī b. Rasūl, vit son indépendance par rapport aux Ayyūbides reconnue par le calife de Bagdad dès 632/1235, c'est toutefois sous le long règne de son fils al-Muzaffar Yūsuf, entre 647/1250 et 694/1295, que la dynastie ancra véritablement son pouvoir dans le pays 9 . Al-Muzaffar Yūsuf parvint à imposer son autorité sur les villes du nord du pays, à Șan'â’ et, de façon plus intermittente, à Șa'da. Il s'empara de la région de Zafāàr (actuel Dhofar) à l'est, assurant ainsi une sécurité sans failles aux navires qui partaient d'Aden pour rejoindre l'Inde en longeant la côte de l'Arabie du Sud ${ }^{10}$. Il resta le principal protecteur de La Mecque et de son sanctuaire pendant tout son règne, y exerçant une influence beaucoup plus profonde que celle des premiers Mamlūks, comme le montrent les sources mecquoises et les documents tirés des recueils d'archives rasūlides ${ }^{11}$.

Archives ? L'évocation de collections conservées pour cette période haute surprendra peut-être le lecteur, tant l'absence de tels documents dans les pays d'Islam, avant la période ottomane, est un fait souvent rappelé et

8. Sur l'histoire politique des Rasūlides, l'étude la plus complète reste à ce jour M. 'Abd al-'Āl, Banū Rasūl wa-banū Ṭāhir wa-'alāqāt al-Yaman al-hāriğiyya fì 'ahdi-himāa, Alexandrie, 1980. Présentation synthétique dans G. Rex Smith, «Politische Geschichte der islamischen Jemen bis zur ersten türkischen Invasion (1-945 Hidschra - 622-1538 n. Chr.) », dans Jemen. 3000 Jahre Kunst und Kultur des glücklichen Arabien, W. Daum (dir.), Innsbruck, 1988, p. 136-154 et J. Chelhod, «L'islam en Arabie du Sud», dans J. Chelhod (dir.), L'Arabie du Sud. Histoire et civilisation 2. La société yéménite de l'Hégire aux idéologies modernes, Paris, 1984, p. 42-49.

9. D. M. Varisco, «Texts and Pretexts: the Unity of the Rasulid State under al-Malik al-Muzaffar», Revue du monde musulman et de la Méditerranée, vol. 67, 1994, p. 13-23.

10. Sur ce point, voir l'étude classique de G. Rex Smith et V. Porter, «The Rasulids in Dhofar in the VII ${ }^{\text {th }}$-VIII ${ }^{\text {th }} /$ XIII ${ }^{\text {th }}-$ XIV ${ }^{\text {th }}$ Centuries ", Journal of the Royal Asiatic Society, vol. 1, 1988, p. 26-44, complétée par É. Vallet, L'Arabie marchande. État et commerce sous les sultans rasūlides du Yémen (626-858/1229-1454), Paris, 2010, p. 608-619 (abrégé: L’Arabie marchande).

11. É. Vallet, ibid., p. 456-458. 
commenté ${ }^{12}$. Le Yémen rasūlide présente pourtant dans ce domaine une situation singulière, qui ne s'explique pas seulement par les conditions favorables de conservation et de préservation des manuscrits dans les hautes montagnes de l'Arabie. Le règne d'al-Muzaffar Yūsuf se distingue en effet par une intense activité rédactionnelle, sans commune mesure avec les dynasties précédentes ${ }^{13}$. «Il nous a vaincu par ses calames » aurait dit l'imam zaydite al-Mutahhar, qui fut son principal concurrent dans le nord du Yémen ${ }^{14}$. On ne peut mieux signifier la rupture profonde dans le régime de l'écrit, de sa production et de ses usages administratifs, que connut le Yémen de la seconde moitié du XIII ${ }^{e}$ siècle. Deux manuscrits, récemment découverts et publiés, en témoignent tout particulièrement. Le premier est un recueil de documents divers produits par l'administration rasūlide à l'époque d'al-Muzaffar Yūsuf, et réunis par son successeur et fils le sultan al-Ašraf 'Umar en un volume unique, que les chercheurs désignent désormais sous le nom de Nūr al-ma ârifif ${ }^{15}$. Postérieur de quelques années, l'atlas fiscal et administratif édité sous le nom d'Irtifä́ al-dawla al-mu'ayyadiyya montre bien la sophistication des méthodes et des savoirs à l'œuvre au sein des bureaux rasūlides à la fin du VII $/ \mathrm{XIII}^{\mathrm{e}}$ siècle $^{16}$. Un recueil plus tardif, celui du sultan al-Afḍal al-'Abbās, élaboré dans la seconde moitié du viII $/ \mathrm{XIV}^{\mathrm{e}}$ siècle et publié en fac-similé il y a dix ans, contient aussi une table fiscale datant de l'époque d'al-Muẓaffar Yūsuf, témoignant ainsi de la conservation de certains documents sous forme d'archive, selon des modalités qui nous échappent largement ${ }^{17}$.

Au terme de cette "chaîne» de production archivistique, le Mulahhas al-fitan, traité administratif rédigé en 815/1412 par un secrétaire du sultan al-Nāșir Ahmad, exhumé dès 1956 par Claude Cahen, s'appuie encore sur ces données fiscales conservées au sein de l'administration sultanienne

12. Voir par exemple les réflexions fondatrices de Cl. Cahen, «Du Moyen Âge aux Temps Modernes », dans J. Berque et D. Chevallier (dir.), Les Arabes par leurs archives (XVIe-XXe siècles), Paris, 1976, p. 11-12 et l'ouvrage récent issu des travaux de la Société des historiens médiévistes français, L'Autorité de l'écrit au Moyen Âge (Orient-Occident), Paris, 2009, en particulier les contributions de Ch. Picard, «De l'usage de l'écrit documentaire en Islam», p. 127-141 et de S. Denoix et B. Galland, «La constitution des "corpus" : rapport introductif », p. 239-261.

13. Pour une présentation générale de ces archives et des enjeux de leur collation, se reporter à É. Vallet, L'Arabie marchande, p. 69-111 et du même, «Pratiques de l'écrit et exercice du pouvoir au miroir des archives rasūlides ( $\mathrm{VII}^{\mathrm{e}}-\mathrm{IX}^{\mathrm{e}} / \mathrm{XIII}^{\mathrm{e}}-\mathrm{XV}^{\mathrm{e}}$ siècle) », à paraître.

14. Ibn 'Abd al-Mağīd, Bahğat al-zaman fì ta'rīh al-Yaman, éd. 'A. al-Hibšī et M. A. al-Sanabānī, Șan'ā', 1988, p. 172 (abrégé: Bahğat al-zaman).

15. Ce titre lui a été donné par son éditeur moderne à partir d'une indication contenue dans le texte. Nūr al-ma'āriffī nuzum wa-qawānīn wa-a'rāf al-Yaman fī l-'ahd al-muzaffarī al-wārif / Lumière de la connaissance. Règles, lois et coutume du Yémen sous le règne du sultan rasoulide al-Muzaffar, éd. M. Ğāzim, Șan'ā', 2003-2005, 2 vol. (abrégé: Nūr al-ma'ārif). Voir sur ce recueil É. Vallet, "Décrire et analyser les archives rasūlides. Le cas de Nūr al-ma ārif», Chroniques yéménites, vol. 14, 2007, p. 63-67.

16. Anonyme, Irtifā' al-dawla al-mu'ayyadiyya, éd. M. Ğāzim, Șan'ā’, 2008.

17. Al-Afḍal al-'Abbās, The Manuscript of al-Malik al-Afḍal. A Medieval Arabic Anthology from the Yemen, Londres, 1998, p. 146-148. 
pour dresser un état complet - et certainement très idéalisé - des revenus du pays $^{18}$. Son ouvrage est tout aussi précieux par la description qu'il livre des différents bureaux (dīwān pl. dawāwīn) à l'origine de cette riche production manuscrite ${ }^{19}$. À côté des secrétaires financiers (dīwān al-kabìr, dīwān al-h̄āșș, dīwān al-ğalāl, hizāna) qui occupent le devant de la scène, l'auteur détaille aussi les fonctions d'autres secrétaires parmi lesquels ceux de la chancellerie (kuttāb al-inš̄') :

Les secrétaires de la chancellerie auguste (al-inšă al-saìd): ce sont les secrétaires de l'auguste rouleau (kuttāb al-darğ al-sa'īd) [chargés de] la rédaction des décrets (manāšìr sg. manšūr), des édits (murabba'āt), des exemptions fiscales (musāmahăāt), des lettres (mukātabāt) envoyées en tout lieu, là où se manifestent les ordres du roi (amr al-malik) et des décrets de concession fiscale (man̄̄̌šri al-iqțāa ât $)^{20}$.

Ce passage constitue, dans toute la production administrative rasūlide, la seule mention précise et détaillée des activités d'une véritable chancellerie. Sur l'ensemble de la période, les documents conservés dans les archives rasūlides se concentrent presque exclusivement sur la matière financière. Aucun recueil ne contient de copie des lettres, décrets ou édits émis par la chancellerie rasūlide. La réunion des archives du sultanat, la composition de ces collections ou traités que nous venons de citer, leur conservation jusqu'à aujourd'hui témoigne de l'intérêt que les sultans portèrent à leur administration. Mais il s'agissait pour eux avant tout de mieux connaître leur territoire et leurs ressources, de fixer les traits d'un État en cours de formation, non de conserver le souvenir des traits de bravoure littéraire dont leurs secrétaires avaient pu être capables dans la rédaction de leur correspondance.

Plus encore, aucun exemple de lettre diplomatique originale n'a été pour l'heure repéré dans les fonds d'archives ou de bibliothèques yéménites. Certes, il n'est pas interdit de rêver que l'on retrouve un jour dans les riches bibliothèques publiques et surtout privées du Yémen un recueil de lettres du même type que le manuscrit Arabe 4440 de la Bibliothèque Nationale de France, mais cela reste peu probable. Les seuls témoignages épistolaires intégraux ayant survécu sont trois copies de documents tardifs émanant du sultanat rasūlide, conservées dans des ouvrages non-yéménites datant du début $\mathrm{du} \mathrm{IX}^{\mathrm{e}} / \mathrm{XV}^{\mathrm{e}}$ siècle:

18. Al-Šarīf al-Husaynī, Mulahhaș al-fițan wa-l-albāb wa-mișbāh al-hudā li-l-kuttāb, Milan, Bibliotheca Ambrosiana, H 130, fol. 4v.-27v. (abrégé: Mulahhhas al-fitan). Voir Cl. Cahen et R. B. Serjeant, «A Fiscal Survey of the Medieval Yemen. Notes preparatory to a critical edition of Mulakhkhas al-fitan [sic] of al-Hasan b. 'Alī al-Sharîf al-Husaynī», Arabica, vol. 5, 1957, p. 22-33 et la traduction anglaise de R. B. Serjeant et G. Rex Smith parue sous le titre: A Medieval Administrative and Fiscal Treatise from the Yemen. The Rasulid Mulakhkhas al-fitan of al-Hasan b. 'Alīal-Husaynī, Oxford, 2007. Le texte n'a pas fait l'objet d'une édition arabe complète à ce jour.

19. Mulahhas al-fitan, fol. 7v.-11r. / traduction anglaise de R. B. Serjeant et G. Rex Smith, ibid., p. 21-31.

20. Ibid., fol. 9 r. (notre traduction). 
- une lettre envoyée par le sultan rasūlide al-Ašraf Ismā'īl au sultan Barqūq en 798/1395-1396, par l'intermédiaire du marchand kārimī Burhān al-Dīn al-Mahallīi, recueillie dans la grande encyclopédie d'al-Qalqašandī, Șubḥ

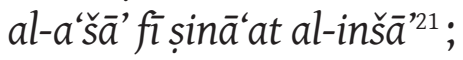

- une lettre envoyée par le sultan rasūlide al-Nāșir Ahmad en rabī' I 819/ mai 1416, conservée par Ibn Hiğğa (m. 837/1434) au sein du Qahwat al-inšă, collection d'une partie de la correspondance des sultans al-Mu'ayyad Šayh et al-Z̄āhir Barsbāy ${ }^{22}$;

- une autre lettre du même sultan datée de ramadān ou šawwāl 821/octobrenovembre 1418, adressée elle aussi à al-Mu'ayyad Šayh, et reproduite dans la notice biographique que l'éminent historien mecquois Taqī al-Dīn al-Fāsī (m. 832/1429) consacra à l'émir de La Mecque, Hasan b. 'Ağlān ${ }^{23}$. Trois lettres pour 225 ans de règne, la moisson documentaire est bien maigre!

Comment comprendre cette lacune, dans un contexte global pourtant favorable à la conservation de l'écrit gouvernemental ? De nombreux indices montrent que la chancellerie, le dìwān al-inšă', ne s'est jamais constituée au Yémen comme un véritable milieu professionnel et culturel. La description bien tardive du Mulahhas al-fițan citée plus haut paraît refléter un idéal d'organisation bureaucratique, sans doute bien éloigné des pratiques réelles. Au milieu du vIII / XIV siècle, le Masālik al-abșār d'Ibn Faḍl Allāh al-'Umarī, qui s'appuie sur le témoignage contemporain d'Ibn al-Burhān, un ancien secrétaire du sultan rasūlide al-Mu'ayyad Dāwūd (696-721/1296-1321), montre assez bien qu'il n'existait pas à cette date de service spécialisé et hiérarchisé, s'occupant exclusivement de la rédaction des diplômes et de la correspondance diplomatique. Au contraire, tout membre de l'administration entourant le sultan pouvait se retrouver chargé de rédiger une lettre, en fonction de son talent et du bon vouloir du souverain:

À propos de la chancellerie (kitābat al-inšāa), Ibn al-Burhān dit: En ce qui concerne les secrétaires de la chancellerie chez [ce souverain], il n'y a pas un seul chef qui est à leur tête, qui lit ce qui est adressé au sultan et répond à sa place, qui reçoit les décisions (marāsīm) et qui les met à exécution (yunaffidi). $\mathrm{Au}$ contraire, si le sultan a besoin d'écrire des lettres (kutub), il envoie à chacun d'entre eux ce qu'il doit écrire. Quand un secrétaire a fait ce qui lui a été ordonné d'écrire, il l'envoie par l'intermédiaire d'un eunuque, qui le présente au sultan. Il l'en informe et le fait appliquer ${ }^{24}$.

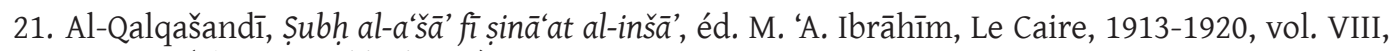
p. 72-76 (abrégé: Șubḥ al-a ‘ $\left.̌^{\prime} \bar{a}^{\prime}\right)$.

22. Ibn Hị̆ğa, Kitāb Qahwat al-inšă’, éd. R. Veselý, Beyrouth, 2005, p. 162-166 (n³9).

23. Al-Fāsīi, Al-'iqd al-taminn fì ta'rīh al-balad al-amīn, éd. F. Sayyid, vol. IV, p. 132-133, reprise par Ibn Fahd, continuateur d'al-Fāsī, dans Itḥāf al-warā bi-ahbāar Umm al-Qurā, éd. F. M. Šaltūt, La Mecque, 1983-1990, vol. III, p. 558-559.

24. Al-‘Umarī, Masālik al-abșār, p. 160. 
À la différence des sultans mamlūks d'Égypte, les souverains du Yémen sont en effet parfaitement arabisés ${ }^{25}$. Tous les membres de la dynastie, y compris al-Muzaffar Yūsuf, reçurent une éducation très soignée ${ }^{26}$. Son fils al-Mu'ayyad Dāwūd, qui devint sultan en 697/1297, était réputé pour ses talents de poète et presque tous les membres de la dynastie se voient créditer d'une œuvre plus ou moins abondante dans des domaines aussi variés que l'astronomie, la médecine, l'histoire ou l'agronomie ${ }^{27}$. Rien d'étonnant donc à ce que le souverain joue ici, d'après Ibn Faḍl Allāh al-'Umarī, le rôle qu'assumait en Égypte le kātib al-sirr, chef de la chancellerie ${ }^{28}$. À la différence du Caire, les secrétaires employés à la rédaction des actes et des correspondances princières n'ont jamais occupé une place d'honneur au Yémen. Ils sont très rarement mentionnés dans les sources locales, qu'il s'agisse des chroniques ou des recueils de biographie, pourtant très prolixes au $\mathrm{VIII}^{\mathrm{e}} / \mathrm{XIV}^{\mathrm{e}}$ siècle ${ }^{29}$. Lorsqu'ils apparaissent, leur activité dans la chancellerie s'accompagne souvent d'autres charges ${ }^{30}$. Cette discrétion et cet effacement

25. C'est sous le règne d'al-Muzaffar Yūsuf que la famille au pouvoir, rejetant ses origines turcomanes, se mit à revendiquer une ascendance gassānide, pour mieux affirmer les liens qui l'unissaient avec les autres tribus du Yémen, appartenant toutes à cette grande famille des Arabes du Sud, descendants de Qahțān. Voir G. Rex Smith, «The Ayyubids and Rasulids: the Transfer of Power in $7^{\text {th }} / 13^{\text {th }}$ Yemen », Islamic Culture, vol. 43, 1969, p. 175-188.

26. Voir par exemple al-Hुazrağ̄ī, Al-'uqūd al-lu'lu'iyya fì ta'rīh al-dawla al-rasūliyya, éd. Bā Sayūnī 'Asil revue par M. al-Akwa', Șan'ā', 1983, vol. I, p. 234, abrégé: Al-'uqūd al-lu’lu’iyya (connaissances d'al-Muzaffar Yūsuf dans le domaine du fiqh, du hadith et de la médecine), Ibn 'Abd al-Mağ̄ìd, Bahğat al-zaman, p. 179-180 (portrait de l'éducation idéale reçue par al-Mu'ayyad Dāwūd) ou al-Ğanadī, Al-sulūk fì țabaqāt al-'ulamā' wa-l-mulūk, éd. M. al-Akwa', Șan'ā', 1989, vol. II, p. 577, abrégé: Al-sulūk (Ibn 'Abd al-Mağ̄ìd enseignant la grammaire, naḥū, au jeune al-Muğāhid 'Alī, héritier présomptif).

27. L'inventaire complet des œuvres attribuées aux sultans se trouve dans 'A. al-Hibšī, Mașādir al-fikr al-istāmī fì l-Yaman, Abou Dhabi, 2004, p. 633-661. Il regroupe au total 39 titres, émanant des six principaux souverains de la dynastie.

28. Voir sur les fonctions de ce personnage à l'époque ayyūbide et mamlūke, Ibn Šìt, Kitāb ma ālim al-kitāba wa-maḡānim al-ișāba, éd. M. H. Šams al-Dīn, Beyrouth, 1988, p. 44, repris par al-Qalqašandī, Șubh al-a šs̄á, vol. IV, p. 30.

29. Sur l'historiographie rasūlide, voir É. Vallet, «L'historiographie rasūlide (Yémen, $\mathrm{XIII}{ }^{\mathrm{e}}-\mathrm{XV}^{\mathrm{e}}$ siècle)», Studia Islamica, vol. 102-103, 2006, p. 35-70. On relève chez al-Ḩazrağ̄̄, Al-'uqūd al-lu'lu'iyya, principale chronique de la dynastie, trois personnages seulement désignés comme kātib al-inšă' à la cour entre 626/1229 et 803/1400, deux sous le règne d'al-Mu'ayyad Dāwūd, Muhammad b. 'Alī al-Ša'bī, mort en 718/1318 (vol. I, p. 256) et Tāğ al-Dīn 'Abd al-Bāqī, devenu célèbre sous le nom d'Ibn 'Abd al-Mağīd, mort en 742/1342 (vol. I, p. 342); un sous le règne d'al-Afụal al-'Abbās, Wağ̄ih al-Dīn 'Abd al-Raḥmān b. 'Alī b. 'Abbās al-Muqri' (vol. II, p. 169). Le recueil de biographie d'al-Ğanadī (m. ap. 530/1330) permet d'ajouter deux noms: Abū Muhammad 'Abd Allāh 'Alī b. Ğa'far, kātib al-inšă' au début du viII' $/ x_{1}{ }^{e}$ siècle (Al-sulūk, vol. II, p. 354) et Ḥasan b. Aḥmad b. Nașr b. 'Alī connu comme Muhtār al-Dawla, passé au service d'al-Muğāhid 'Alī dans les années 720/1320 (Al-sulūk, vol. II, p. 144-145).

30. Muhtār al-Dawla fut en charge à la fois du Trésor (hizāna) et de la chancellerie (al-Ğanadī, Al-sulūk, vol. II, p. 144-145) et Wağīh al-Dīn 'Abd al-Raḥmān al-Muqri' était à la fois vizir, qāḍ̂ al-quḍāt et chancelier (al-Hुazrağ̄i , Al-'uqūd al-lu'lu'iyya, vol. II, p. 169). Quant à Ibn 'Abd al-Mağ̄îd, le sultan al-Mu'ayyad Dāwūd ne lui demandait rien d'autre dans le cadre de ses fonctions «si ce n'est d'enseigner la grammaire à son fils al-Muğāhid» (al-Ğanadī, Al-sulūk, vol. II, p. 577). Ibn 'Abd al-Mağ̄id est resté célèbre comme historien, auteur de la chronique inachevée, Bahğat al-zaman fi ta'rīh al-Yaman. 
sont d'autant plus frappants que les détenteurs d'autres fonctions administratives, en particulier financières (vizirs, mustawfi, nāzir), sont abondamment mentionnés dans ces mêmes sources ${ }^{31}$.

Seul le personnage de Mūsā b. al-Ḥasan al-Mawșilī fait exception dans ce paysage. Outre la notice que lui consacre Ibn Ḥağar al-'Asqalānī, le juriste al-Ğanadī (m. ap. 730/1330), rédacteur du principal recueil de țabaqāt des savants, souverains et hommes de pouvoir du Yémen rasūlide, l'évoque en un long développement ${ }^{32}$. Chez ces deux auteurs, Mūsā b. al-Ḥasan al-Mawșili est invariablement présenté comme le responsable du dīwān al-inša $\bar{a}$, seule fonction administrative qu'il aurait assumée à la cour sultanienne durant de longues années, depuis son arrivée dans les années 660/1260 jusqu'à sa mort en 699/1300, lors d'un déplacement du souverain rasūlide à $\mathrm{Aden}^{33}$. Al-Mawșilī aurait même été, aux dires du secrétaire Ibn 'Abd al-Mağ̄id, qui fut un temps au service d'al-Mu'ayyad Dāwūd, l'unique rédacteur de la correspondance adressée par le Rasūlide al-Muẓaffar Yūsuf aux sultans mamlūks ${ }^{34}$. Aucune de ses lettres n'a pour autant été conservée ${ }^{35}$. Seul le Burd a survécu, en étant copié et diffusé dans des cercles d'abord yéménites puis égyptiens ${ }^{36}$. Peut-on cependant le considérer comme un témoignage fidèle des normes en vigueur dans la chancellerie rasūlide à partir de la seconde moitié du $\mathrm{VII}^{\mathrm{e}} / \mathrm{XIII}^{\mathrm{e}}$ siècle?

À cette question, nous ne pouvons apporter de réponse univoque. À aucun moment, le Burd ne mentionne la dynastie sultanienne du Yémen, ni même le sultan al-Muzaffar Yūsuf. La préface d'al-Mawșilī reste vague sur les destinataires de son compendium. Son intention explicite est d'offrir un modèle (imtitīall) à ceux qui ont « dans ce domaine [= l'inšă’] un cœur dévoué

31. Voir à titre d'exemple l'étude que nous avons pu mener sur les surintendants de la douane d'Aden (nāzirir 'Adan): É. Vallet, L'Arabie marchande, p. 265-275 et annexe, p. 735-742 (tableau prosopographique des surintendants d'Aden, comprenant 28 personnages ayant exercé leur charge entre 647/1250 et 837/1434).

32. Al-Ğanadī, Al-sulūk, vol. II, p. 566-567.

33. Les précisions sur sa mort sont données par al-Ğanadī. Ibn Hağar ne donne aucune date dans sa notice. Les activités d'al-Mawșilī sont attestées jusqu'à peu de temps avant sa mort: Ibn 'Abd al-Mağ̄ìd mentionne deux vers rédigés dans une correspondance de 696/1296 au sultan al-Ašraf ainsi que les lettres (mukātabāt) qu'il envoya dans toutes les régions du royaume au moment de l'avènement du nouveau sultan al-Mu'ayyad Dāwūd en muharram 696/novembre 1296 (Bahğat al-zaman, p. 175 et 177).

34. Ibn Ḥağar al-'Asqalānī, Durar, vol. IV, p. 374, n¹017. Voir la traduction ci-dessus, correspondant à la note 7 .

35. Al-Hazrağ̄î, Al-'uqūd al-lu'lu'iyya, vol. I, p. 234 donne un bref extrait d'une missive adressée à al-Z̄āhir Baybars, dans laquelle le sultan al-Muẓaffar Yūsuf demandait l'envoi d'un médecin égyptien dans la cité de Zafār nouvellement conquise. Peut-être fut-elle rédigée par al-Mawșilī?

36. Deux manuscrits du Burd ont été repérés à ce jour. Le premier fut réalisé en 748/1348 (Dār al-Kutub $848 \mathrm{Adab}$ ) à partir d'un original conservé à Zabīd, d'après les indications du colophon. Il contient une lacune au début du second chapitre, présente dans l'original selon le copiste. L'autre copie du même ouvrage (Dār al-Kutub 188 Adab Tīmūr) a été effectuée en 898/1488, vraisemblablement par un copiste égyptien, qui a ajouté au Burd un développement comprenant des exemples de mukātabāt wa-ad iyya mișriyya. Cette seconde copie est en outre amputée de l'introduction et de la première partie de l'ouvrage (voir introduction du Burd, p. 12-13). 
et un entendement excellent les plaçant au plus haut ${ }^{37} »$. Nulle dédicace au souverain, nulle réponse à une commande princière donc, mais un ouvrage rédigé à l'initiative de l'auteur lui-même et destiné à une petite élite de spécialistes de la langue et de l'adab. La préoccupation d'abord linguistique d'al-Mawșilī est d'ailleurs perceptible en de nombreux passages du texte. Le premier chapitre débute ainsi avec des considérations générales sur les rapports entre signifiants ( $a l f \bar{a} z$ ) et signifiés ( $\left.m a a^{\prime} \bar{a} n \bar{l}\right)$ lorsque l'on prononce un discours emphatique. Plus le signifié est général dans une comparaison, plus celle-ci est élogieuse. Dire «Zayd est le plus généreux des hommes» (Zayd akram al-nās) est plus éloquent (ablag்) que «Zayd est le plus généreux de ses frères » (Zayd akram banī abīhi), rappelle al-Mawșilīi ${ }^{38}$. Ce principe fondamental, qui peut nous paraître bien trivial, sous-tend nombre de ses explicitations ultérieures. Aussi les titres qui doivent être utilisés pour s'adresser à un souverain dans une correspondance officielle sont-ils hiérarchisés en fonction de la réalité concrète à laquelle ils renvoient: al-maqām (le lieu où se tient le souverain) et al-maqarr (le lieu où il siège) sont, selon al-Mawșilī, plus dignes d'emploi qu'al-abwāb (les portes) ou al-'atabāt (les marches) ${ }^{39}$. Par le jeu des métaphores, les convenances de la correspondance princière se modèlent ici directement sur une topographie symbolique tirée du cérémonial. D'autres passages de l'ouvrage confirment cette prédilection d'al-Mawșilī pour ce cadre d'analyse fondé sur la lexicographie, dans lequel les mots et les choses entretiennent un rapport concret et direct ${ }^{40}$.

De ce point de vue, le Burd diffère profondément de ses principaux équivalents égyptiens d'époque ayyūbide et mamlūke, qu'il s'agisse du Kitāb ma'ālim al-kitāba wa-maḡānim al-ișāba d'Ibn Šìt (m. 625/1228), du Ta'rîf bi-l-muștalaḥ al-šarîf d'Ibn Faḍl Allāh al-'Umarī (m. 749/1348), du Tataîf al-ta'rîf d'Ibn Nāẓir al-Ğayš (m. 788/1386) ou du Șubḥ al-a'š ša' fi șinā'at al-inšă' d'al-Qalqašandī (m. 821/1418). Tous ces traités de chancellerie tiennent un discours normatif sur l'art de la correspondance (al-mukātabāt), dans lequel ils n'hésitent pas à inclure des considérations d'ordre lexicographique ou rhétorique. Toutefois, aucun n'en fait le fondement ou le point de départ de son exposé à l'instar d'al-Mawșilī. L'approche de ces secrétaires cairotes est uniment diachronique ou historique, à commencer par Ibn Šìt, qui distingue systématiquement les formulaires retenus à son époque ( fì yawminā had $\bar{a}$ ) de ceux qui prédominaient autrefois. Rien n'est plus éloigné des conceptions qui ont présidé à l'écriture des chapitres du Burd. Ibn Šìt, non content de souligner ce que les usages de son temps avaient de neuf ou d'inédit, explique les évolutions terminologiques par de simples glissements de

37. Burd, p. 46.

38. Ibid., p. 48.

39. Ibid., p. 54-55.

40. Ibid., p. 59-60 (al-mağlis et al-ğināb); p. 62-63 (al-amīr et al-nā’ib); p. 68 (al-șadr et al-mu'tabar); p. 79-84 (sur les laqab). 
conventions, laissant deviner une compréhension spécifique du langage comme ensemble de codes formels. Il rappelle par exemple que les titres d'al-maqām et d'al-maqarr ne furent pas de tout temps appliqués au souverain, et que leur introduction, à une date qu'il ne précise pas, entraîna la dévaluation du titre d'al-mağlis, délaissé par les sultans et adopté dès lors par leurs serviteurs les plus importants, vizirs ou grands cadis ${ }^{41}$. Que l'on compare cette présentation à ce que dit al-Mawșilī d'al-maqām et al-maqarr, et l'on verra tout ce qui sépare la démarche de ces deux auteurs. Les traités d'Ibn Faḍl Allāh al-'Umarī et d'Ibn Nāẓir al-Ğayš sont eux aussi marqués par cette conscience de la labilité des phrases et des termes usités dans les correspondances officielles. Leurs ouvrages sont marqués par un réel souci d'actualiser le formulaire épistolaire sultanien en fonction des évolutions politiques de leur époque, ce qui les amène à envisager le traitement des divers souverains et dignitaires de l'État les uns après les autres ${ }^{42}$. Rien de tel chez al-Mawșilī dont le traité ne donne aucun nom précis de souverain ou de personnage.

Dépouillé de tout marqueur historique fort, le traité d'al-Mawșilī doit-il être envisagé en dehors de son contexte de production? Deux indices permettent toutefois d'affirmer que le Burd porte bel et bien la trace de son berceau yéménite. Parmi les destinataires des missives gouvernementales, il évoque tout d'abord une catégorie d'hommes de pouvoir propres à la péninsule Arabique : les ašrāf, descendants du Prophète, qui exerçaient une grande partie du pouvoir dans le nord du Yémen et au Hiğāz depuis le $\mathrm{IV}^{\mathrm{e}} / \mathrm{x}^{\mathrm{e}}$ siècle en se réclamant de la doctrine zaydite ${ }^{43}$. Al-Mawșilī indique qu'il convient de distinguer en eux ce qui relève de l'«honneur prophétique» (al-šaraf al-nabawī) dont ils sont les héritiers et ce qui relève d'une autorité affirmée par la force (imāra), qui conduit à les désigner plus fréquemment sous le nom d'émirs (amīr pl. umarā' $)^{44}$. De fait, cet usage est bel et bien observé dans les sources yéménites où les grandes familles de chérifs du nord du Yémen et de La Mecque sont appelées suivant une terminologie émirale: l'usage diplomatique préconisé par al-Mawșilī rejoint ici l'usage

41. Ibn Šìt, Kitāb ma'ālim al-kitāba wa-maġānim al-ișāba, p. 59-60. Selon l'éditeur (p. 58 note 4), le plus ancien usage du titre al-maqām est attesté dans une lettre d'un vizir 'abbāside au sultan salğ $\bar{q}$ ide Sanğar (m. 1157).

42. Voir Ibn Faḍl Allāh al-'Umarī, Al-ta'rîf bi-l-muștalaḥ al-šarīf, Le Caire, 1312 H, p. 4-90 (chapitre 1, «sur les différentes catégories de correspondance », fì rutab al-mukātabāt) et Ibn Nāẓir al-Ğayš, Kitāb tațqîf al-ta'rîf bi-l-muștalah al-šarîf, éd. R. Veselý, Le Caire, 1987, p. 9 sqq. («correspondances des califes, des rois, des gouvernants et des grands », mukātabāt al-huulafä' wa-l-mulūk wa-l-hukkām wa-l-akābir).

43. Sur l'implantation de ces descendants du Prophète, voir D. T. Gochenour, The Penetration of Zaydi Islam into Early Medieval Yemen, Harvard, 1984, thèse de doctorat inédite et sur les chérifsémirs de La Mecque, R. T. Mortel, "The Genealogy of the Hasanids Sharifs of Mecca», Journal of the College of Arts, King Saud University, vol. 12-2, 1985, p. 221-250 et R. T. Mortel, «Zaydi Shi'ism and the Hasanid sharifs of Mecca», International Journal of the Middle East Studies, vol. 19, 1987, p. 455-472.

44. Burd, p. 62. 
courant $^{45}$. Notons qu'aucune distinction de ce type n'est formulée dans les traités égyptiens de chancellerie qui ne consacrent que des développements minimaux aux descendants du Prophète ${ }^{46}$.

Le développement concernant les correspondances avec les marchands est plus significatif encore du contexte yéménite dans lequel le Burd fut élaboré. Al-Mawșilī distingue en effet, de façon tout à fait inhabituelle pour la tradition égyptienne, différents ensembles de marchands:

Ils sont de trois catégories: pour ceux qui partent pour l'Égypte et la Syrie et tous ceux qui voyagent dans le Kārim égyptien (man sāfara fí al-kārim al-mișrī), on désigne leurs notabilités ( $a^{i} y \bar{a} n$ ) sous le nom de qādì. Ils sont classés selon leur rang (marātib): le plus élevé d'entre eux est appelé al-mağlis al-sāmī al-qāạ̄, et en-dessous, mağlis al-qāḍ̄; en-dessous encore al-qāḍ̄; celui qui vient d'une lignée de juristes (min bayt al-fiqh) et est connu par ses activités marchandes, on l'appelle al-faqih. [...]

Ceux qui voyagent vers l'Inde, on s'adresse à leurs notabilités en disant mağlis al-șadr, ou al-șadr tout seul; ceux qui occupent une position intermédiaire (awsāț) sont appelés al-nāhud $\bar{a}^{47}$. De même, celui qui vient de l'Inde est appelé al-nāhudā, qui est son surnom honorifique (laqab). Quant au reste [de ces marchands], on les désigne avec leur surnom honorifique (laqab). [...]

Tous ceux dont la région (iqlìm) est le Yémen, on leur écrit en disant al-šayh. Au plus éminent, on dit mağlis al-šayh ; [un rang] en-dessous, al-šayh̆, et ceux qui occupent une position intermédiaire, al-șadr. Le reste, avec le laqab ${ }^{48}$.

Cette nomenclature, assez obscure au premier abord, prend un tout autre relief lorsqu'on la compare avec les documents, règlements et liste de gratifications accordées aux marchands, conservés au sein des archives du port d'Aden pour la seconde moitié du viI $/ \mathrm{XIII}^{\mathrm{e}}$ siècle ${ }^{49}$. Y apparaissent de manière parfaitement claire non seulement la division des marchands en trois catégories (marchands du Kārim circulant entre l'Égypte et l'Inde;

45. L'exemple le plus frappant est celui des descendants de l'imām zaydite Hamza désignés systématiquement sous le nom d'umarā' Banī Hamza. Voir par exemple ce passage reproduit dans al-Hुazrağ̄i, Al-'uqūd al-lu'lu'iyya, vol. I, p. 93 : «L'imam [zaydite Aḥmad b. al-Husayn] entra dans Șan'ā' le septième jour du même mois [ğumadā I 648], et avec lui, l'ensemble des ašrāf; les tribus l'approuvèrent et il gouverna (istawalā) Șan'ā' et son district ( $\left.a^{\prime} m \bar{a} l\right)$ puis Damār et ses environs. Les émirs hamzides étaient avec lui. Mais il ne leur faisait pas confiance et réciproquement. » Les émirs ḥamzides font partie des ašrāf accompagnant l'imām, mais tous les ašrāf ne sont pas émirs.

46. Voir par exemple al-Qalqašandī, Șubḥ al-a šă', vol. IV, p. 37-38.

47. Ce terme, emprunté au persan (nāw, navire et hū $\bar{d} \bar{a}$, maître), désigne le propriétaire d'un navire. Les nāhudā musulmans jouèrent à partir du $x^{e}$ siècle un rôle décisif dans les liaisons entre les différentes rives de l'océan Indien. Voir R. Chakravarti, « Nakhudas and Nauvittakas: Ship-Owning Merchants in the West Coast of India (c. AD 1000-1500), Journal of the Economic and Social History of the Orient, vol. XLII, 2000, p. 34-64.

48. Burd, p. 73.

49. Nūr al-ma'ārif, vol. I, p. 492-524; traduction dans É. Vallet, Grands ports du Yémen médiéval. Documents traduits des archives rasūlides, à paraître, documents 1-3. 
nāhudāa de l'Inde ; marchands du Yémen ${ }^{50}$ ), mais aussi la hiérarchie des titres interne à chaque catégorie ${ }^{51}$. Nul doute qu'al-Mawșilī reprenne ici encore les usages en vigueur au Yémen et que son point de vue s'affirme comme résolument extérieur à l'Égypte, désignée comme une destination lointaine, et non comme point de départ ou origine. Le Burd est bel et bien un «produit » du sud de la péninsule Arabique, ce que le titre même de l'ouvrage laissait déjà entendre ${ }^{52}$.

Dans les deux passages que nous venons de commenter, al-Mawșilī ne fait pas œuvre d'innovateur. Il décrit des usages protocolaires qui existaient déjà avant lui, comme l'emploi du titre d'émir pour les descendants du Prophète, ou celui de nāhudāa pour les marchands de l'Inde, autant de réalités vivantes sur lesquelles il porte son regard de lexicographe. Al-Mawsilī ne fait pas non plus véritablement œuvre de compilateur. Il ne fait de référence explicite à aucun autre kātib ou adīb, sauf dans son dernier chapitre, recueil de vers utiles en toute circonstance, où il cite pêle-mêle Abū Tammām, al-Mutanabbī, Abū Nuwās et d'autres auteurs moins célèbres ${ }^{53}$. Le cœur de son ouvrage, toutefois, apparait essentiellement comme une mise en ordre, une classification hiérarchisée de termes, de titres et de formules, tirés de sa pratique quotidienne de la chancellerie. Al-Mawșilī systématise et complète des usages sans doute déjà existants. Il est en ce sens, et en ce sens seulement, inventeur d'une nouvelle norme épistolaire dans le Yémen rasūlide.

De cette activité ordonnatrice déployée dans la seconde moitié du VII $/$ XIII ${ }^{e}$ siècle, le recueil d'archives du sultan al-Afḍal al-'Abbās, constitué au cours des années 770/1370, a gardé une trace singulière et intéressante. Une notice d'une page environ y récapitule les différents titres qui étaient utilisés par la chancellerie rasūlide lorsqu'elle s'adressait aux plus hauts personnages du royaume, essentiellement dans le nord du Yémen et le Hị̆ğàz (fașl fì al-muhāțabāt), ainsi qu'aux princes et aux rois musulmans et nonmusulmans (fașl al-mulūk) ${ }^{54}$. Ce document non daté énumère notamment le sultan mamlūk, les princes musulmans et chrétiens d'Abyssinie et divers rois de l'Inde. Parmi eux, la mention des maîtres hindous de Nahrawalā

50. Sur ces différentes catégories à l'époque rasūlide, voir É. Vallet, L'Arabie marchande, p. 362-366 (marchands du Yémen), p. 505-516 (marchands du Kārim) et p. 589-600 (nāhuudā de l'Inde).

51. En particulier pour les marchands de l'Inde, Nūr al-ma'ārif, vol. I, p. 515-516 et 519. La distinction d'une catégorie de marchands «intermédiaires» (mutawassit al-hāl) apparaît aussi dans le règlement du port d'Aden (Nūr al-ma'ārif, vol. I, p. 498; trad. É. Vallet, Grands ports du Yémen médiéval, document $1, \S 18$ ).

52. Le burd (unité burda pl. abrād) est en effet une étoffe rayée à base de laine servant à envelopper le corps, comme manteau ou couverture. Le Yémen était particulièrement réputé pour sa fabrication avant même les débuts de la période islamique (voir R. P. A. Dozy, Dictionnaire détaillé des noms des vêtements chez les Arabes, Amsterdam, 1845, p. 59-64 et R. B. Serjeant, Material for a History of Islamic Textiles up to the Mongol Conquests, Londres, 1942-1951, p. 243).

53. Burd, p. 190-193, 202.

54. Al-Afụal al-'Abbās, The manuscript of al-Malik al-Af̣̣al. A Medieval Arabic Anthology from the Yemen, p. 390. 
et de Sumnāt permet de rapporter cette notice à la période fondatrice d'al-Muzaffar Yūsuf, dans la seconde moitié du VII ${ }^{\mathrm{e}} / \mathrm{XIII}^{\mathrm{e}}$ siècle, avant que les deux principautés du Gujarat (Nahrawalā) et du Kathiawar (Sumnāt) ne tombent entre les mains du sultan de Delhi, à partir de la fin de ce même siècle ${ }^{55}$. Or, les titres employés dans ce formulaire correspondent parfaitement aux indications données par al-Mawșilī dans son Burd. L'ensemble du document est organisé suivant une hiérarchie claire, mettant au sommet les souverains d'Égypte, d'Iraq (Ilhānat) et d'Inde, ainsi que le dā'̄i ismaélien

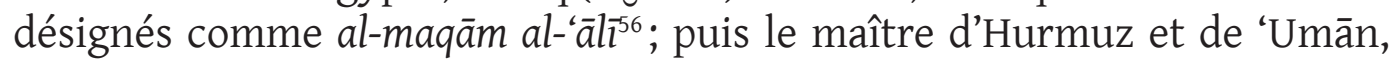
sous suzeraineté du Kirmān, qualifié d'al-ğināb al-'ālī, comme s'il était vizir du prince du Kirmān. Au plus bas se trouvent les maîtres de Dahlak, Sawākin et Maqdišūh qualifiés d'al-šayh al-ağall, tant leur souveraineté s'exerce sur un nombre de personnes réduit ${ }^{57}$. Seuls les princes non-musulmans paraissent échapper à cette échelle hiérarchique, à l'instar du négus d'Éthiopie (al-hạțī) qui se voit attribuer le titre al-sulțān al-kabīr al-muğall (?) qui n'apparaît à aucun endroit dans le Burd. Recopiée à la suite de textes de nature très variée, sur l'ordre du sultan al-Afḍal al-'Abbās (m. 778/1377), cette notice se trouvait sans aucun doute parmi les documents conservés dans la proximité du souverain. Fut-elle élaborée par al-Mawșilī lui-même? Sa date probable de rédaction et ses nombreux points communs avec le contenu du Burd rendent cela vraisemblable, à défaut d'être certain. Il est en effet fort possible qu'al-Mawșilī ait élaboré, à côté de son traité fixant les bases théoriques de la correspondance, des formulaires pratiques à l'usage des autres secrétaires de la chancellerie yéménite.

Quoi qu'il en soit, la préservation, par des voies différentes, de cette notice et du traité d'al-Mawșilī, ne relèvent pas du pur hasard. Elles témoignent au contraire d'un intérêt persistant, encore à l'œuvre dans la seconde moitié du VIII ${ }^{\mathrm{e}} / \mathrm{XIV}^{\mathrm{e}}$ siècle, pour la conservation et transmission d'un "ordre épistolaire » mis en place dans la seconde moitié $\mathrm{du} \mathrm{vII}{ }^{\mathrm{e}} / \mathrm{XIII}^{\mathrm{e}}$ siècle. Pourquoi, dans ces conditions, ne pas avoir conservé les lettres écrites par al-Mawșilī? Plusieurs raisons peuvent être envisagées, à commencer par la nature du protocole diplomatique lui-même. Mis à part quelques mentions fugitives, le texte même des missives diplomatiques ne reçoit pas au Yémen les honneurs de la chronique ${ }^{58}$. D'une part, elles ne circulent pas, leur contenu précis ne

55. Sur les relations entre le Gujarat et le Yémen, voir É. Vallet, «Les sultans rasūlides du Yémen, protecteurs des communautés musulmanes de l'Inde ( $\mathrm{VII}^{\mathrm{e}}-\mathrm{VIII} / \mathrm{XIII}^{\mathrm{e}}-\mathrm{XIV}^{\mathrm{e}}$ siècles) », Annales Islamologiques, vol. 41, 2007, p. 149-176 et E. Lambourn, «India from Aden - Khuţba and Muslim Urban Networks in Late Thirteenth-Century India», dans K. Hall (éd.), Secondary Cities and Urban Networking in the Indian Ocean Realm, c. 1000-1800, Lanham, 2008, p. 55-97.

56. Comparer avec Burd, p. 75.

57. Ils rentrent dans la catégorie des mašā’hh al-buldān identifiée par al-Mawșilī, Burd, p. 66.

58. La chronique d'al-Ḩazrağ̄i ne conserve ainsi que la copie intégrale d'une seule lettre, reçue par le sultan al-Ašraf Ismā'īl en 795/1393 (Al-'uqūd al-lu'lu’iyya, vol. II, p. 204-205). Voir la traduction de ce document dans É. Vallet, «Les sultans rasūlides du Yémen, protecteurs des communautés musulmanes de l'Inde», p. 169-171. 
semble pas connaitre une diffusion importante au moment où elles sont lues ou écrites: les chroniqueurs préfèrent en effet enregistrer les gestes accomplis au moment des ambassades (remise de robe d'honneur, etc.) sans chercher à reproduire le contenu des missives, dont on ne sait même pas si elles étaient lues en public ${ }^{59}$. D'autre part, ces lettres ne semblent pas faire l'objet d'un archivage durable, sous quelque forme que ce soit, en tout cas rien qui soit consultable par les auteurs postérieurs.

Il faut bien se rendre à l'évidence: le contenu propre des lettres diplomatiques, même chargées d'ornements stylistiques et de morceaux de bravoure en prose rimée (sağ), n'intéressait guère dans le Yémen rasūlide. Seuls les répertoires de titulatures et de formules diplomatiques, reflets des hiérarchies constitutives de l'État, se devaient d'être conservés et transmis. Pour le reste, les princes du Yémen et leur cour ne semblent pas avoir goûté les délices de l'adab de chancellerie, peu valorisé par rapport aux genres poétiques qui retinrent, eux, toutes les faveurs du pouvoir. Dans le sud de la Péninsule, la poésie émane en effet de toute part. Mémoire des querelles entre tribus, satire ou louange des puissants, éloge des mérites d'une ville ou d'une région ${ }^{60}$, la poésie reste le langage politique par excellence. Il n'est donc pas indifférent que le souvenir de Mūsā b. al-Hasan al-Mawșilī ait d'abord été conservé au Yémen en tant que poète, plus qu'en tant que maître de la chancellerie sultanienne. Dans le recueil de tabaqāt d'al-Ğanadī, al-Mawșilī est en effet d'abord présenté comme «chef du groupe des poètes» de son temps, ra's țabaqāt al-šu 'arā'. Transmetteur au Yémen des œuvres linguistiques d'Ibn al-Ḥăğib, Mūsā b. al-Ḥasan était aussi selon al-Ğanadī, généreux et accueillant en sa demeure qui était le théâtre de grands banquets où pouvaient rivaliser les talents poétiques de ses hôtes ${ }^{61}$.

59. Voir à titre d'exemple le récit de l'ambassade égyptienne venue au Yémen en 703/1303 telle qu'elle est rapportée par Ibn 'Abd al-Mağīd qui en fut un témoin direct (Bahğat al-zaman, p. 225-227). L'envoyé, venu d'Égypte pour annoncer la victoire des musulmans sur les Mongols, fut accueilli dans la citadelle de Ta'izz, siège du pouvoir rasūlide, en présence des notables de l'État (a'yān al-dawlat al-šarīfa) et des émirs, au cours de l'audience du souverain (al-maqām al-šarîf al-sulțānì). Ibn 'Abd al-Mağīd cite ensuite l'extrait d'un poème composé pour l'occasion, mettant en avant l'émerveillement de l'envoyé devant la majesté du sultan rasūlide. Puis, le sultan ordonna d'emmener l'émissaire demeurer en un lieu qui convenait à sa condition et le combla de faveurs. L'ambassadeur repartit quelques temps plus tard avec la réponse du sultan scellée et les présents envoyés au souverain d'Égypte. Rien n'est dit, à aucun moment, du contenu des lettres échangées. Sur les rituels diplomatiques du Yémen rasūlide, voir plus largement notre article, «Du système mercantile à l'ordre diplomatique, le bassin de la mer Rouge entre Yémen rasūlide et Égypte mamlūke (VII $-\mathrm{IX}^{\mathrm{e}} / \mathrm{XIII}^{\mathrm{e}}-\mathrm{XV}^{\mathrm{e}}$ siècle) », dans Les relations diplomatiques au Moyen Âge. Actes du XLI congrès de la SHMESP, Paris, 2011.

60. Voir la controverse en vers de la vigne et du palmier évoquée dans notre article, «La vigne et le palmier. Identités provinciales et construction de l'État sous le sultanat rasūlide (XIII$\mathrm{XV}^{\mathrm{e}}$ siècle)», Revue des mondes musulmans et de la Méditerranée, vol. 121-122, 2007, p. 53-67. Sur la poésie yéménite à l'époque rasūlide, voir 'Abd Allāh al-Hibšī, Hāayat al-adab al-yamanī fì 'așr Banī Rasūl, Șan'ā', 1980.

61. Al-Ğ̉anadī, Al-sulūk, vol. II, p. 567. Deux vers d'al-Mawșilī sont cités par Ibn 'Abd al-Maǧīd, Bahğat al-zaman, p. 175. 
Cette association étroite du kātib al-inšă ' avec la poésie de cour ne se limite pas au cas de notre auteur. On la retrouve aussi chez quelques uns de ces trop rares personnages dont les sources ont conservé la mémoire au Yémen. Ainsi en va-t-il d'Abū Muhammad 'Abd Allāh b. 'Alī, connu comme le « lettré du Yémen» (adïb al-Yaman), poète ayant chanté les louanges des deux sultans al-Muzaffar Yūsuf et d'al-Mu'ayyad Dāwūd, qui devint kātib al-inšă' dans les premières années $\mathrm{du} \mathrm{VIII}^{\mathrm{e}} / \mathrm{XIV}^{\mathrm{e}}$ siècle ${ }^{62}$. Il en est pareillement de Muhammad b. 'Alī al-Ša'bī (m. 718/1318), passé au service du même sultan al-Mu'ayyad: «Il avait un savoir solide (dirāya țābita) et il disait de la poésie excellente » nous rapporte le chroniqueur al-Hazrağīà la suite d'al-Ğanad̄̄ ${ }^{63}$. Mais l'exemple le plus parlant est sans nul doute offert par le parcours d'Ibn 'Abd al-Mağīd, venu à la cour âgé d'une vingtaine d'années. Son histoire du Yémen, Bahğat al-zaman, ne manque pas de détails sur les compositions poétiques (qașida) qu'il présenta au sultan, à commencer par une controverse en vers opposant les mérites du sabre et du calame qui ouvrit sa carrière auprès du souverain en 704/1304, alors qu'il n'avait que vingt-trois ans ${ }^{64}$. Après un séjour de quelques années en Syrie, il revint servir le sultan al-Mu'ayyad Dāwūd comme kātib al-inš $\bar{a}^{\prime 65}$. Particulièrement discret sur ses activités dans le cadre de ses fonctions, Ibn 'Abd al-Mağīd n'hésite pas, en revanche, à retranscrire certains des poèmes qu'il composa en l'honneur de son maître ${ }^{66}$.

La qașida, sommet et accomplissement de l'inšă': l'œuvre entreprise au Yémen par al-Mawșilī ne fut donc pas sans lendemains. Loin d'être une production typique de l'«esprit» de la chancellerie mamlūke, comme l'avait imaginé son éditrice, le Burd al-muwašša fí șinăat al-inšă' témoigne au contraire de la façon dont a été établi à partir de la seconde moitié du XIII ${ }^{e}$ siècle un «ordre épistolaire» spécifique dans le contexte propre du Yémen rasūlide. Ordre nouveau, comme le montre l'absence de toute référence historique à une tradition de chancellerie antérieure à cette dynastie sultanienne; ordre singulier, comme l'atteste l'absence d'emprunts massifs aux usages de la chancellerie égyptienne ayyūbide puis mamlūke; ordre se voulant universel, enraciné dans une approche lexicographique faisant des mots et des expressions le reflet naturel et fidèle de l'ordre des choses. Plus que comme un savoir historique, c'est finalement comme pratique littéraire, trouvant son sommet dans la maîtrise de l'art poétique, qu'al-Mawșilī développa au service d'al-Muzaffar Yūsuf, un langage du pouvoir raffiné, qui ouvrait son auguste maitre, fils d'un ancien général turcoman, aux vastes horizons de l'arabité.

62. Al-Ğanadī, Al-sulūk, vol. II, p. 354.

63. Ibid., p. 413; al-Hुazrağ̄̄, Al-‘uqūd al-lu'lu’iyya, vol. I, p. 256.

64. Ibn 'Abd al-Mağ̄ìd, Bahğat al-zaman, p. 242.

65. Ibid., p. 281.

66. Ibid., p. 253, 255, 270-273. 


\section{Bibliographie}

\section{Sources}

Al-AfḌAl AL-'ABBĀs b. 'Alī b. Dāwūd b. Yūsuf b. 'Umar al-Rasūlī, The Manuscript of al-Malik al-Afdal. A Medieval Arabic Anthology from the Yemen, éd. en fac-similé et introd. par G. R. Smith \& D. M. Varisco, Londres, E. J. W. Gibb Memorial Trust, 1998.

Anonyme, Nūr al-ma'āriffī nuzum wa-qawānīn wa-a'rāf al-Yaman fìl-'ahd al-muzaffarī al-wārif / Lumière de la connaissance. Règles, lois et coutume du Yémen sousle règne du sultan rasoulide al-Muzaffar, éd. Muhammad Ğāzim, Șan'ā', CEFAS, 2003-2005, 2 vol.

Anonyme, Irtifā' al-dawla al-mu'ayyadiyya, éd. Muḥammad Ğāzim, Șan'ā’, CEFASDAI, 2008.

AL-F̄̄sī, Al-'iqd al-tamīn fïta'rīh al-balad al-amīn, vol. I (éd. Muhammad al-Ṭayyib / Ḥāmid al-Fiqqī), vol. II-VII (éd. Fu'ād Sayyid), vol. VIII (éd. Mạ̣mūd al-Ṭanāhīi), Le Caire, Maṭba'at al-sunna al-muhammadiyya, 1959-1969, rééd. Beyrouth, 1985-1986.

AL-ĞANADī, Al-sulūk fì țabaqāt al-'ulamā' wa-l-mulūk, éd. Muhammad al-Akwa', Șan'ā', Wizārat al-i'lām wa-l-țaqāfa, 1983-1989, 2 vol.

Al-HुAzRAĞ̄̄, Al-'uqūd al-lu'lu'iyya fì ta'rīh al-dawla al-rasūliyya, éd. Bā Sayūnī 'Asil revue par Muhammad al-Akwa', Șan'ā', Markaz al-dirasāt wa-l-buhūt alyamaniyya, 1983, 2 vol; trad. anglaise J. W. Redhouse, in The Pearl Strings. A History of the Resúliyy Dynasty of Yemen, Londres, Luzac and Co (E. J. W. Gibb Memorial Series), 1906, 2 vol.

IBN 'ABD AL-MAĞīD, Bahğat al-zaman fì ta'rīh al-Yaman, éd. Abd Allāh al-Hibšî/ Muḥammad Aḥmad al-Sanabānī, Șan'ầ', 1988.

IBN Faḍl AllāH AL-'Umarī, Masālik al-abșār fì mamālik al-amṣār, éd. Ayman Fu'ād Sayyid, Le Caire, IFAO, 1985 [concernant le Yémen].

IBN Faḍl AlLĀH AL-'UMARĪ, Al-ta'rîf bi-l-mușțalaḥ al-šarîf, Le Caire, 1312 H.

IBN FAHD, Itḥāf al-warā bi-aḩbār Umm al-Qurā, vol. I-III, éd. Fahīm Muhammad Šaltūt; vol. IV, éd. 'Abd al-Karīm 'Alī Bāz; vol.V, index préparés par Muhammad Ismā'îl al-Sayr Aḥmad et Șādiq al-Bīlī Muhammad Abū Šāwī, La Mekke, Ğāmi'at Umm al-Qurā, 1983-1990. 
IBN HִAĞAR AL-'ASQALĀNī, Al-durar al-kāmina fī a'yān al-mi'a al-țāmina, éd. Sālim al-Karnūkī, Hayderabad, Mațba'at mağlis dā’irat al-ma'ārif al-‘utmāniyya, 1929-1931.

IBN ḤıĞĞA, Kitāb qahwat al-inšā' / Das Rauschgetränk der Stilkunst oder Qahwat al-Inšă', éd. Rudolf Veselý, Beyrouth (Orient-Institut Beirut, Biblioteca Islamica, Band 36), 2005.

IBN NĀẒIR AL-ĞAYš, Kitāb tațqîf al-ta'rīf bi-l-mușțalah al-šarīf, éd. Rudolf Veselý, Le Caire, IFAO, 1987.

IBN ŠĩT, Kitāb ma'ālim al-kitāba wa-maḡānim al-iṣāba, éd. Muḥammad Ḥusayn Šams al-Dīn, Beyrouth, Dār al-kutub al-'ilmiyya, 1988.

Al-MawșiL̄i, Tāğ al-Dīn Mūsā b. al-Hasan, Al-burd al-muwaššā fī șināat al-inšā', éd. 'Afāf Sayyid Șabra, Beyrouth, Dār al-kutub al-'ilmiyya, 1990.

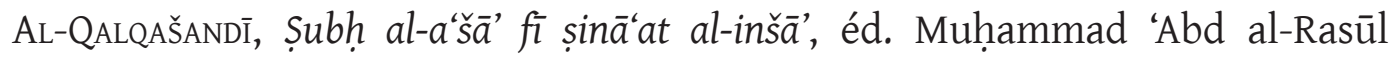

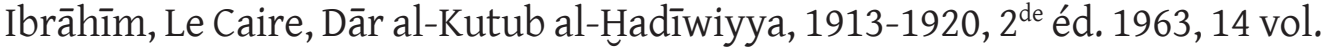

\section{Études}

'ABD AL-'ĀL, Muhammad, Banū Rasūl wa-banū Ṭāhir wa-'alāqāt al-Yaman al-ḩ̄āriğiyya fì ‘ahdi-himā, Alexandrie, al-Hay’a al-mișriyya al-‘āmma li-l-kitāb, 1980.

CAhen, Claude et Serjeant, Robert B., "A Fiscal Survey of the Medieval Yemen. Notes preparatory to a critical edition of Mulakhkhas al-fitan [sic] of al-Hasan b. 'Alī al-Šarīf al-Ḥusaynī», Arabica, vol. 5, 1957, p. 22-33.

CAHEN, Claude, «La correspondance de Diyā' al-Dīn ibn al-Athīr, liste de lettres et de textes de diplômes ", Bulletin of the School of Asian and African Studies, vol. XIV, 1952, p. 34-43.

CAHEN, Claude, "Du Moyen Âge aux Temps Modernes", dans J. Berque et D. Chevallier (dir.), Les Arabes par leurs archives (XVI $-\mathrm{XX} \mathrm{X}^{e}$ siècles), Paris, CNRS, 1976, p. 11-12.

ChAKRAVARTI, Ranabir, «Nakhudas and Nauvittakas: Ship-Owning Merchants in the West Coast of India (c. AD 1000-1500), Journal of the Economic and Social History of the Orient, vol. XLII, 2000, p. 34-64.

CHELHoD, Joseph, «L'islam en Arabie du Sud», dans J. Chelhod (dir.), L'Arabie du Sud. Histoire et civilisation 2. La société yéménite de l'Hégire aux idéologies modernes, Paris, Maisonneuve et Larose, 1984, p. 13-55. 
Denoix, S. et B. Galland, «La constitution des "corpus": rapport introductif », dans L'Autorité de l'écrit au Moyen Âge. Orient-Occident, Paris, Publications de la Sorbonne, 2009, p. 239-261.

Dozy, R. P. A., Dictionnaire détaillé des noms des vêtements chez les Arabes, Amsterdam, Jean Muller, 1845.

Gochenour, D. T., The Penetration of Zaydi Islam into Early Medieval Yemen, PhD, Université de Harvard, 1984.

AL-Ḥibšī, 'Abd Allāh, Hayāt al-adab al-yamanī fì 'aṣr Banī Rasūl, Șan'ā', Wizārat al-i'lām wa-l-țaqāfa al-yamaniyya, 1980.

AL-Ḥibšĩ, 'Abd Allāh, Mașādir al-fikr al-islāmīfîl-Yaman, Abou Dhabi, Al-Muğamma‘

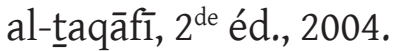

LAmbouRn, Elizabeth, «India from Aden - Khuțba and Muslim Urban Networks in Late Thirteenth-Century India», dans K. Hall (éd.), Secondary Cities and Urban Networking in the Indian Ocean Realm, c. 1000-1800, Lanham, Lexington Books, 2008, p. 55-97.

L'Autorité de l'écrit au Moyen Âge. Orient-Occident, Paris, Publications de la Sorbonne, 2009.

MoRTEL, Robert T., "The Genealogy of the Hasanids Sharifs of Mecca », Journal of the College of Arts, King Saud University, vol. 12/2, 1985, p. 221-250.

MORTEL, Robert T., "Zaydi Shi'ism and the Hasanid sharifs of Mecca», International Journal of the Middle East Studies, vol. 19, 1987, p. 455-472.

PICARD, Ch., "De l'usage de l'écrit documentaire en Islam», dans L'Autorité de l'écrit au Moyen Âge. Orient-Occident, Paris, Publications de la Sorbonne, 2009, p. 127-141.

Smith, G. Rex, «The Ayyubids and Rasulids: the Transfer of Power in $7^{\text {th }} / 13^{\text {th }}$ Yemen », Islamic Culture, 43, 1969, p. 175-188, repris dans Studies in Medieval History of the Yemen and South Arabia.

Smith, G. Rex, «Politische Geschichte der islamischen Jemen bis zur ersten türkischen Invasion (1-945 Hidschra - 622-1538 n. Chr.)», dans W. Daum (dir.), Jemen. 3000 Jahre Kunst und Kultur des glücklichen Arabien, Innsbruck, Pinguin Verlag, 1988, p. 136-154. 
Smith, G. Rex et Porter, Venetia, "The Rasulids in Dhofar in the VII ${ }^{\text {th }}-$ VIII ${ }^{\text {th }} /$ XIII $^{\text {th }}-$ XIV $^{\text {th }}$ Centuries ", Journal of the Royal Asiatic Society, vol. 1, 1988, p. 26-44, repris dans Studies in Medieval History of the Yemen and South Arabia.

SERJEANT, Robert B., Islamic Textiles: Material for a History up to the Mongol Conquests, Londres, 1942-1951.

SERJEANT, Robert B. et SMith, G. Rex, A Medieval Administrative and Fiscal Treatise from the Yemen. The Rasulid Mulakhkhas al-fitan of al-Hasan b. 'Alì al-Husaynī, Oxford, Oxford University Press, 2007.

VALLET, Éric, «Décrire et analyser les archives rasūlides. Le cas de Nūr al-ma'ārif», Chroniques yéménites, vol. 14, 2007, p. 63-67.

VALLET, Éric, «L'historiographie rasūlide (Yémen, XIII ${ }^{\mathrm{e}}-\mathrm{XV}^{\mathrm{e}}$ siècle) », Studia Islamica, vol. 102-103, 2006, p. 35-70.

VALLET, Éric, «Les sultans rasūlides du Yémen, protecteurs des communautés musulmanes de l'Inde ( $\mathrm{VII}^{\mathrm{e}}-\mathrm{VIII} / \mathrm{XIII}^{\mathrm{e}}-\mathrm{XIV}^{\mathrm{e}}$ siècles) », Annales Islamologiques, vol. 41, 2007, p. 149-176.

VALLET, Éric, «La vigne et le palmier. Identités provinciales et construction de l'État sous le sultanat rasūlide (XIII ${ }^{\mathrm{e}}-\mathrm{XV}^{\mathrm{e}}$ siècle) », Revue des mondes musulmans et de la Méditerranée, vol. 121-122, 2007, p. 53-67.

VALLET, Éric, L'Arabie marchande. État et commerce sous les sultans rasūlides du Yémen (626-858/1229-1454), Paris, Publications de la Sorbonne (Bibliothèque historique des pays d'Islam, 1), 2010.

VALLET, Éric, « Du système mercantile à l'ordre diplomatique, le bassin de la mer Rouge entre Yémen rasūlide et Égypte mamlūke (VII $-\mathrm{IX}^{\mathrm{e}} / \mathrm{XIII}^{\mathrm{e}}-\mathrm{XV}^{\mathrm{e}}$ siècle)», dans Les relations diplomatiques au Moyen Âge. Actes du XLI congrès de la SHMESP, Paris, Publications de la Sorbonne, 2011, p. 269-301.

VALlet, Éric, «Pratiques de l'écrit et exercice du pouvoir au miroir des archives rasūlides $\left(\mathrm{VII}^{\mathrm{e}}-\mathrm{IX}^{\mathrm{e}} / \mathrm{XIII}^{\mathrm{e}}-\mathrm{XV}^{\mathrm{e}}\right.$ siècle) », dans S. Decroix (dir.), L'exercice des pouvoirs à l'âge des sultanats, IFAO, à paraître.

Vallet, Éric, Grands ports du Yémen médiéval. Documents traduits des archives rasūlides, IFAO, à paraître.

VARISCO, Daniel M., "Texts and Pretexts: the Unity of the Rasulid State under al-Malik al-Muzaffar », Revue du monde musulman et de la Méditerranée, vol. 67, 1994, p. 13-23. 